\title{
A System-of-Systems Framework for Performance Assessment in Complex Construction Projects
}

Jin Zhu

Civil and Environment Engineering

Department, College of Engineering

and Computing,

Florida International University

Jzhuoo6@fiu.edu
Ali Mostafavi

OHL School of Construction,

College of Engineering and Computing,

Florida International University

almostaf@fiu.edu
DOI 10.5592/otmcj.2014.3.2

Research paper

\section{Keywords}

Construction project, Performance assessment, Systems-Of-Systems, Bottom-Up Approach
Performance inefficiency is a CRITICAL Challenge faCing the CONSTRUCTION INDUSTRY. DESPITE THE EFFORTS MADE IN THE EXISTING BODY OF LITERATURE, AN INTEGRATED THEORY OF PERFORMANCE ASSESSMENT FACILITATING A BOTTOM-UP UNDERSTANDING OF THE DYNAMIC BEHAVIORS, UNCERTAINTIES, AND INTERDEPENDENCIES BETWEEN THE CONSTITUENTS IN CONSTRUCTION PROJECTS IS STILL MISSING. The traditional paradigm for performance assessment is mainly based on a reductionism perspective, in which construction projects are identified as monolithic systems. However, complex construction projects are systems-of-systems. Systems-of-systems have unique traits that are different from those of monolithic systems. Failure to investigate construction projects as systems-of-systems has led to theoretical and methodological limitations in the creation of integrated tools and techniques for better assessment of performance in complex construction projects. To address these theoretical and methodological limitations, a system-of-systems framework is proposed as a theoretical lens and methodological structure toward creation of tools and techniques for integrated performance assessment of complex construction projects. Two principles (i.e., base-level abstraction and multi-level aggregation) are used to develop the proposed framework. The proposed framework facilitates a bottom-up evaluation of the dynamic behaviors, uncertainties, and interdependencies between the constituents in construction projects. The capabilities of the proposed framework show its potential in addressing the limitations pertaining to the traditional frameworks for performance assessment. Hence, it can be adopted and tested by researchers to advance the body of knowledge and create integrated theories of performance assessment in complex construction projects. 


\section{INTRODUCTION}

Performance inefficiency continues to be a major challenge in the construction industry. Over the past few decades, project management tools and technologies have been created to improve the performance of construction projects. Despite the efforts made to enhance their performance, construction projects still suffer from low efficiency. A large number of construction projects are shown to be unable to meet their planned performance objectives in terms of time and cost. According to a recent study conducted by the Construction Industry Institute (CII), out of the 975 owner-submitted projects being investigated, only $5.4 \%$ met both their authorized cost and schedule within an acceptable margin, while nearly $70 \%$ had actual costs or schedules exceeding $10 \%$ deviation from their authorized values (CII, 2012).

Traditional tools and techniques for performance assessment in construction projects (e.g., work breakdown structure and critical path method) are rooted in a reductionism perspective toward projects (He et al., 2009). This reductionism perspective considers construction projects as monolithic systems, which are "a set of different elements connected or related so as to perform a unique function not performable by the elements alone" (Rechtin, 1991). Considering construction projects as monolithic systems, the majority of the studies related to performance assessment in construction projects follow a top-down approach. The top-down approach regards a construction project as an assemblage of processes and activities and views a project statically (Lyneis et al., 2001). The top-down approach in performance assessment of construction projects fails to abstract construction projects at an appropriate level, in which the dynamic behaviors, uncertainties, and interdependencies can be captured. Levitt (2011) has classified these traditional tools and methods as the "PM
1.0" paradigm. The PM 1.0 paradigm originated in the Project Management Body of Knowledge (PMBOK) in the early 1970s. The PM 1.0 paradigm adopts detailed, centralized planning, decentralized execution and centralized control in project management. The top-down style of performance assessment, in accordance with the PM 1.0 paradigm, has proved to be efficient only in analyzing projects in the relatively stable political, economic and technological context of the post-World War II period (Levitt 2011). However, modern construction projects are large, complex projects operating in a dynamic environment. These complex construction projects are composed of multiple interrelated systems, including different processes, activities, players, resources, and information. Changes in one system can also cause unforeseen changes in connected systems, and the causal feedback between these systems causes projects to evolve over time (Taylor and Ford, 2008). Improving the performance of construction projects hinges on a better understanding of the underlying dynamics and interactions between these systems. The PM 1.0 tools and methods for performance assessment have been proven to be incapable of capturing these dynamics and interdependencies in modern construction projects with high levels of complexity and uncertainty (Levitt, 2011; Love et al., 2002). Hence, there is a need for a paradigm shift to address the theoretical and methodological limitations in performance assessment of complex construction projects.

Over the last decade, a new paradigm in the project management field (so called "PM 2.0") has emerged toward agile project management for modern, dynamic and complex projects in the twenty-first century (Levitt, 2011). The PM 2.0 paradigm aims at providing new tools and techniques for effective management of complex projects. However, a key element missing toward the paradigm shift from PM 1.0 to PM 2.0 (in the context of construction project management) is an integrated framework for performance assessment, which facilities capturing the dynamic behaviors, uncertainties and interdependencies between the constituents in project organizations. A close examination of modern construction projects reveals that complex construction projects are systems-ofsystems (SoS). A system-of-systems is defined as "an assemblages of components which individually may be regarded as systems" (Maier, 1998). SoS have different traits from monolithic systems in terms of focus, boundaries, structures, timeframe, and centricity (Gorod et al., 2008). These distinguishing traits are closely related to the dynamic behaviors, uncertainties and interdependencies between constituents in projects and have a great impact on the project performance. Hence, conceptualizing construction projects as SoS and investigating the distinguishing traits of SoS in construction projects could facilitate a better understanding of the performance in complex construction projects. The understanding of complex construction projects as SoS is a critical step toward creating integrated theories for performance assessment and making a paradigm shift in the management of construction projects.

In this paper, a SoS framework is proposed as a theoretical lens and methodological structure toward the creation of PM 2.0 tools and techniques for integrated performance assessment in complex construction projects. In the following sections, first the theoretical and methodological limitations in the traditional performance assessment tools and methods are discussed. Then, complex construction projects are evaluated with respect to the distinguishing traits of SoS to demonstrate the need for conceptualizing construction projects as SoS. Accordingly, a construction project 
system-of-systems (CPSoS) framework is proposed for bottom-up assessment of performance. The capabilities of the proposed framework are demonstrated in terms of addressing the theoretical and methodological limitations of the traditional paradigms for integrated performance assessment in construction projects. Finally, different avenues for future research related to creating an integrated theory of performance assessment using the proposed framework are discussed.

\section{Theoretical and \\ Methodological Limitations in Existing Literature}

Different studies related to performance assessment have been conducted to investigate the critical factors and strategies for the enhancement of construction project performance. In one stream of research, different methods have been created for predicting the performance of construction projects in terms of time and cost. This kind of analysis is also called "ex-ante" performance assessment. In ex-ante analysis, construction simulation models (e.g., Cyclone by Halpin (1977), STROBOSCOPE by Martinez (1996), and Simphony by Hajjar and AbouRizk (1999)) have been created for prediction of performance in construction projects. The level of abstraction in the existing construction simulation paradigms is at the process or activity level. The interdependencies between different processes and the uncertainties in durations of activities have been considered in these simulation methods. However, the disparity between the simulated and actual project performance measures reveals that the existing simulation methods fail to capture all the complex dynamics and uncertainties affecting the performance of construction projects. For example, the impact of dynamic decision making of human agents, uncertainties in resource quality, and information processing on the project performance cannot be captured in most of the existing simulation tools and methods. Thus, the main limitation of the existing simulation methods is their inability to incorporate the dynamic behaviors, uncertainties and interdependencies between the constituents of construction projects based on a proper level of abstraction.

In another stream of research, "expost" analyses are conducted to identify the critical processes or factors which lead to performance variations in construction projects. This stream of research is mainly based on questionnaire surveys and case studies of completed projects. For instance, the existing body of literature has identified external and internal factors, such as the quality of site management, bad weather, poor human resource management and labor strike (Chan and Kumaraswamy, 1996; Kaliba et al., 2009; Iyer and Jha, 2005), which affect the performance of construction projects. The limitation of these ex-post approaches is that they evaluate the critical factors affecting the performance of construction projects on a one-size-fits-all basis. Each construction project is unique because of the different attributes of constituents (e.g., different behavioral styles of each human agent, or the completeness of each piece of information) and the interdependencies between these constituents. The critical success or failure factors of projects are contingent on the traits of different project organizations. However, without an appropriate level of abstraction and a bottom-up approach to capture the specific traits of different construction projects, existing studies related to expost analysis of performance assessment can only provide one-size-fits-all findings.

The major cause of the limitations in the traditional approaches for performance assessment in construction projects is the inappropriate conceptualization of projects. The traditional performance assessment tools and methods investigate construction projects as monolithic systems. The nature of monolithic system analysis includes static boundaries, hierarchical structure, and process-based methods. These attributes of monolithic system analysis lead to the following limitations in performance assessment of construction projects:

(i) lack of consideration of the autonomy of constituents in projects (e.g., creativity and flexibility of firstline workers),

(ii) lack of consideration of the micro-behaviors of entities (e.g., information processing and decision making),

(iii) lack of consideration of the interdependencies between constituents (e.g., the impact of information uncertainty on the decision-making process of human agents),

(iv) lack of consideration of the existence of emergent properties in project organizations (e.g., the level of resilience as an integrative attribute arising as a result of the interactions between project constituents), and

(v) lack of consideration of the evolving nature of the projects (e.g., the changes in scope, standard, and external environment of construction projects over time).

To address these limitations, the need for a paradigm shift toward integrated performance assessment in construction projects has been recognized in recent studies. Lee et al. (2009) showed that there are context-level factors (e.g., staff skill level, collaboration level, motivation, and inspection level) affecting the performance of construction projects. These factors need to be carefully investigated and analyzed in order to conduct accurate performance assessment and robust project management. CII research evaluated project performance based on the project team's integrative ability to mitigate cost and schedule deviation through the early and accurate prediction of 
cost and schedule outcomes, which is greatly affected by human behavior and organizational culture (CII, 2013). Despite the efforts made in these studies, a framework facilitating integrated performance assessment in complex construction projects, which address the theoretical and methodological limitations in existing research, is still missing.

\section{Point of Departure}

The review of the literature presented in the previous section highlights the theoretical and methodological limitations in performance assessment of construction projects. These limitations are mainly due to the lack of a proper conceptualization of construction projects and the selection of an inappropriate level of abstraction for analysis. Hence, the objective of this paper is to propose a SoS framework for integrated performance assessment in the context of complex construction projects. First, the need for conceptualizing construction projects as SoS is demonstrated. Then, the proposed SoS framework based on the conceptualization is introduced. Finally, the capabilities of the proposed framework in addressing the limitations of the existing performance assessment paradigm and developing a new paradigm for performance assessment are discussed.

\section{Construction Projects as} Systems-of-Systems

Systems thinking is an effective approach in capturing complexity and dynamic interactions in projects (Sheffield et al., 2012). A system, in general, is a collection of components organized to accomplish a specific function or set of functions. There are different types of systems (e.g., monolithic, complex adaptive, and SoS), and each type of system has distinguishing traits (Mostafavi et al., 2011). A successful analysis of projects using systems thinking is contingent on correctly identifying the system type. The traditional approaches for performance assessment in projects have conceptualized projects as monolithic systems. However, this monolithic system perspective has several limitations and fails to provide an integrated framework for performance assessment. Recent studies (e.g., Zhu and Mostafavi, 2014) have suggested that complex projects demonstrate the distinguishing traits of SoS, and hence, should be conceptualized as SoS. Based on this finding, complex construction projects need to be evaluated with respect to the distinguishing traits of SoS to test whether a SoS framework would be appropriate for proper conceptualization of construction projects. The most significant

\begin{tabular}{l|l|}
\hline Traits & Definitions \\
$\begin{array}{l}\text { Operational } \\
\text { independence of the } \\
\text { individual systems }\end{array}$ & $\begin{array}{l}\text { Components systems of SoS are capable of performing } \\
\text { useful operations independently of one another when } \\
\text { disassembled }\end{array}$ \\
\hline $\begin{array}{l}\text { Managerial independence } \\
\text { of individual systems }\end{array}$ & $\begin{array}{l}\text { Component systems of SoS are separately acquired and } \\
\text { integrated but maintain a continuing operational existence }\end{array}$ \\
\hline Emergent properties & $\begin{array}{l}\text { SoS perform functions and carry out purposes that do not } \\
\text { reside in any component systems }\end{array}$ \\
\hline Evolutionary development & $\begin{array}{l}\text { The development of SoS is evolutionary over time with } \\
\text { structure, function, and purpose added, removed, and } \\
\text { modified }\end{array}$ \\
\hline Geographic distribution & $\begin{array}{l}\text { Component systems can readily exchange information } \\
\text { and knowledge with one another without the limitation of } \\
\text { geographic proximity }\end{array}$ \\
\hline
\end{tabular}

Table 1 Distinguishing Traits of SoS

distinguishing traits of SoS include operational and managerial independence, emergent behavior, evolutionary development and geographic distribution (Maier, 1998; Sage and Cuppan, 2001). These traits and their definitions are summarized in Table 1. Systems that possess all or a majority of these distinguishing traits can be recognized as SoS. Accordingly, the existence of these traits are investigated in construction projects to evaluate whether SoS provides a proper theoretical lens for performance assessment.

\section{Operational Independence}

Operational and managerial independence are the two most important traits of SoS. Operational independence means that the component systems, which can also be regarded as sub-systems of the SoS, are capable of fulfilling their own functions and purposes independently. Complex construction projects include different components (a.k.a., sub-systems), such as design, procurement, construction, contract administration, risk management, and safety management. Different sub-systems have their own independent purposes and functions, and are capable of performing useful operations independently of each other. For instance, the function of the design system is to generate the drawings and specifications according to the owner's needs, while the major function of the construction system is to translate designs into the final product facility. Other sub-systems also have their own purposes and functions, including procuring required material and equipment, tracking contract, controlling and mitigating risks, and ensuring safety in construction. Each of these sub-systems consists of different constituents (e.g., human agents, resources, information and tasks) operations in order to fulfill their independent functions. For example, in the design sub-system of a residential construction project, human 
agents (e.g., architecture designers, structural designers and engineers) utilize resources (e.g., computers and design software) and information (e.g., owner's requirements, soil report and building code) to fulfill different tasks, such as discussing the preliminary design with different stakeholders, deciding on the type of foundation and generating drawings for the column and slab. Different subs-systems are then integrated toward the success of the project through interdependencies between these constituents. For example, the drawings generated as the output of the design sub-system then become the important information utilized in construction, risk management and safety management sub-systems. In this way, different sub-systems are integrated as a project network.

\section{Managerial Independence}

Another important trait of SoS is managerial independence. Managerial independence requires that the component systems of SoS not only can operate independently but also do operate independently. In complex construction projects, different sub-systems are separately acquired and they do operate independently. In fact, because of the large scale and high complexity of modern construction projects, it is nearly impossible for a single acquisition or command authority to conduct all the work or implement centralized control over the whole project. Each sub-system in construction projects operates independently by human agents with specific expertise and particular resources. In construction projects, subsystems (e.g., design, procurement, construction, contract administration, risk management, and safety management) are operated and managed by different authorities, such as the design team, purchasing team, contractor and consultant companies. For example, the construction subsystem is operated by the contractor, who has a skilled workforce, certain construction equipment, sufficient cash flow, construction techniques and experience in previous projects as contractors. The successful operation of the construction sub-system needs support and corporation from other sub-systems. However, the core functions are purely realized by the construction sub-system by its own. The other authorities in the project, such as the design team or risk management department, are not capable of directly undertaking any job or offering administrative instructions to the construction process. A similar managerial independence is continuously maintained in other sub-systems of construction projects.

The operational and managerial independence traits in construction projects show that construction projects consist of different components, which individually can be considered as a system. Traditionally, these components are considered as processes or activities in projects and are investigated as a whole. In other words, the level of abstraction in analysis of construction projects is at the process or activity level. Hence, the impacts of the dynamic behaviors, uncertainties and interdependencies between constituents below the process or activity level cannot be captured. Since the traits of complex construction projects show that these components are subsystems consisting of autonomous constituents (e.g. human agent, resource, information and task), a proper level of abstraction which facilitates investigating the attributes of constituents, their dynamic behaviors and interdependencies both inside the subsystems and between sub-systems is needed for a better understanding of project performance.

\section{Emergent properties}

Emergent properties have been defined by Johnson (2006) as "behaviors that stem from interactions between the components of complex systems and the environment." In SoS, when subsystems operate as an integrated system, the network can exhibit emergent properties which do not reside in any individual systems. According to Sage and Cuppan (2001), the main objective for engineering of SoS is fulfilled by these emergent properties. Hence, emergent properties have a significant impact on the performance of SoS. The existence of emergent properties in project organizations has been recognized in recent studies. For example, agility, absorptive capacity, adaptive capacity, and vulnerability have been reported at the project level (Knudsen and Roman, 2004; Karadzic et al., 2013; Zhang, 2007). Zhu et al. (2014) showed that three emergent properties could exist in construction project organizations: absorptive capacity, adaptive capacity, and restorative capacity. These properties are aggregated from dynamic behaviors and interdependencies of constituents in construction projects, but cannot be attributed to any single constituent or sub-systems. For example, adaptive capacity in construction projects refers to the project organization's ability to adjust itself in terms of organizational structure or execution processes in response to undesirable disruption or desirable opportunity in order to maintain or enhance the performance outcomes. The level of adaptive capacity of a project organization is an integrative attribute. It is affected not only by the behaviors of single constituent or sub-system (e.g. speed of decision making of risk manager, or ability to consider different alternatives of the design sub-system), but also the communication and coordination between different subsystems. For instance, bureaucracy in some of the project organizations, which hinders the flow of information between design and construction subsystems, would delay the process of making changes in the project plans to cope with emerging issues on the 
jobsite. Thus, it causes performance deficiency. Hence, integrated performance assessment requires a bottomup approach to aggregate the dynamics and interdependencies in different levels of construction projects to better investigate emergent properties.

\section{Evolutionary Development}

A SoS is not static. Development of SoS is evolutionary with structures, functions and purposes added, removed, and modified over time (Sage and Cuppan, 2001). Construction projects operate in dynamic and evolving environments (Love et al., 2002). Different types of changes in construction projects, typically arising during project execution, influence cost and schedule outcomes. In one study conducted by CII, 10 types of typical changes in construction projects, which could cause deviations in cost and schedule from their baseline values, are summarized as: scope changes; standard, regulatory, and legal requirements; engineering design; work planning and execution; commissioning and start-up; control functions; vendor/ supplier and procurement; economic conditions; legal and social conditions; and force majeure (CII, 2013). Any one of the above-mentioned changes usually affects several sub-systems directly or indirectly, and the causal feedback between these sub-systems causes the whole project to evolve over time. For example, a design error or omission causes changes not only in design sub-system, but also other subsystems such as construction sub-system, procurement sub-system and risk management sub-system. Construction sub-system changes since construction methods may need to be adjusted after the changes in design have been made. Procurement sub-system changes since different material and equipment may need to be obtained because of the changes in design. Risk management sub-system changes since the risk of the project may need to be re-evaluated after the design error or omission has been found. Thus, the final configuration of a construction project is usually totally different from its original plan because of the evolutionary development. This evolutionary trait of construction projects requires a dynamic view in assessing project performance over time.

\section{Geographic Distribution}

Finally, the sub-systems in SoS are geographically distributed. The final products of construction projects are usually constructed in one location. However, the functions of each individual sub-system can be fulfilled at different places. Especially, in a globalized economy and through international collaborations, modern construction projects have different sub-systems (e.g., design, construction, and risk management) operated at different geographic locations, even in different cities or countries. Also, construction materials and equipment can be obtained from a global market easily without the limitation of geographic proximity. In geographically dispersed projects, coordination and communication among the players is paramount for an efficient and effective outcome (Evaristo et al., 2004). For example, in a geographically dispersed construction project with design sub-system and construction sub-system in two different cities, an effective communication mechanism using advanced Information and Communication Technologies (ICT) tools between the two sub-systems will eliminate the possible constructability problems, and thus, improve the project performance in terms of time and schedule. The trait of geographic distribution in the context of construction projects highlights

Construction Project System-of-systems

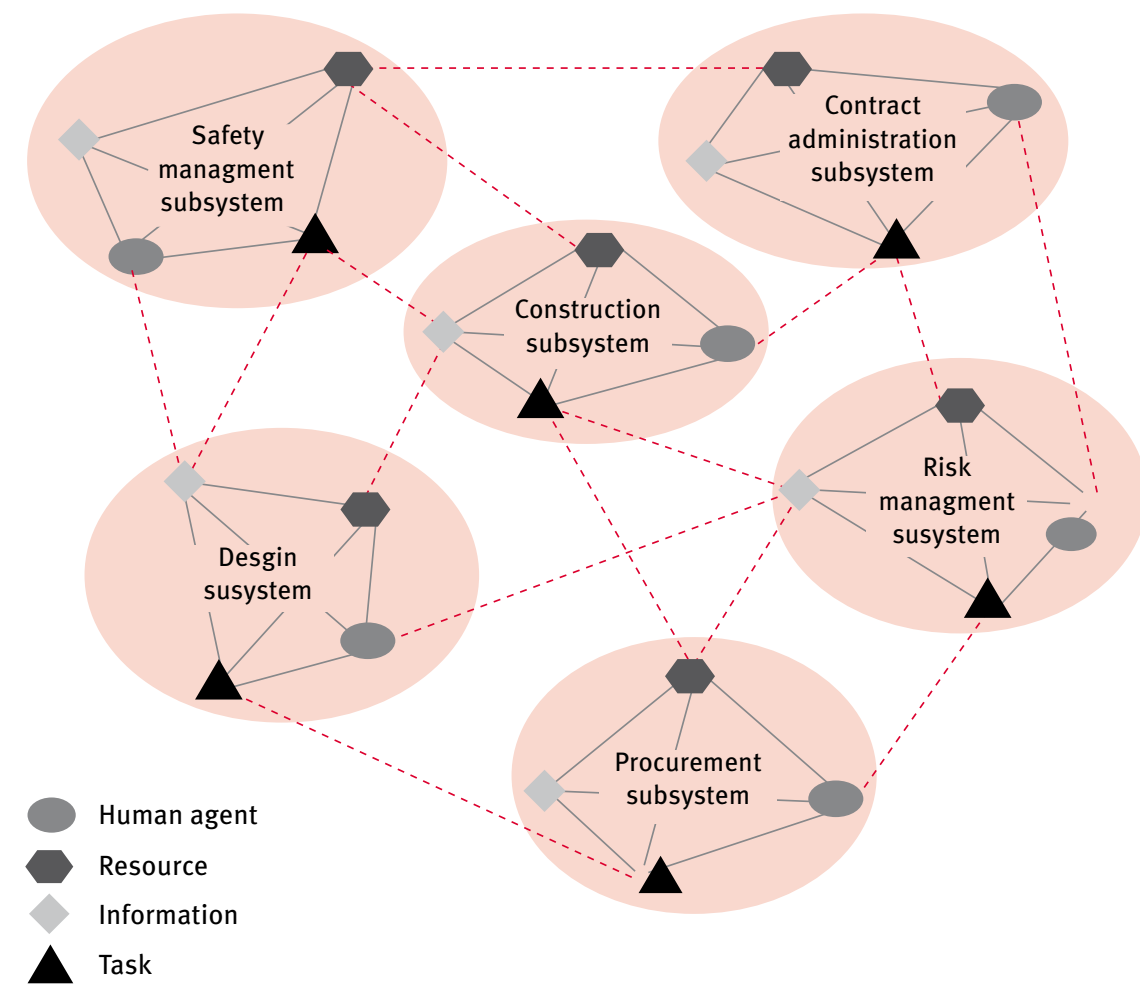

Figure 1 A conceptual model for Construction project systems of systems 
the importance of investigating the interdependencies between different sub-systems through exchange of information on project performance.

By examining the five distinguishing traits of SoS in the context of complex construction projects, it is shown that complex construction projects are SoS and should be investigated as SoS. Figure 1 provides a conceptual model of construction project system of systems (CPSoS) in the format of a metanetwork (i.e. a network of networks). In the conceptual model, different subsystems (e.g., design, construction, procurement, contract administration, risk management, and safety management) operate as independent subsystems. Each of these sub-systems consists of different human agents, resources, information and tasks to fulfill its individual purposes and functions. Through the interdependencies between the constituents (e.g. human agents, resources, information and tasks), different sub-systems interact and integrate for the common goal of project success. The meta-network is a dynamic network, which experience changes in attributes of single nodeand interdependencies between different nodes, because of the evolutionary development of project organizations. Hence, conceptualizing construction projects as SoS provides a proper theoretical lens for performance assessment in construction projects. In addition, such conceptualization highlights the requirements for developing an integrated performance assessment framework based on the distinguishing traits of SoS.

\section{Construction Project Systems- of-Systems Framework for Performance Assessment}

Based on the distinguishing traits of CPSoS investigated in the previous section, a CPSoS framework is proposed in this section as a methodological structure for assessment of performance in construction projects. Two principles are used to develop the CPSoS framework: base-level abstraction and multilevel aggregation.

\section{Base-level abstraction}

The first principle in the CPSoS framework is base-level abstraction. Complex construction projects are conceptualized as SoS with sub-systems consisting of different constituents (e.g., human agents, information, resources and tasks). By capturing the dynamic behaviors, uncertainties and interdependencies of these constituents, the performance of construction projects can be investigated at a proper level of abstraction (i.e., level at which the dynamic behaviors occur in project organizations). Hence, using the principle of base-level abstraction, construction projects are abstracted at the base level in which four types of base constituents exist: human agent, information, resource, and task.

At the base level of CPSoS, there are three types of tasks: production work (e.g., foundation design, or rebar installation), information processing (e.g., obtaining material standards from specifications, or reporting unforeseen conditions in jobsite) and decision making (e.g., making decision on the selection of equipment, or making decision on whether to acquire more workforce to accelerate the project). The majority of the purposes and functions in the projects can be fulfilled by one or multiple tasks of the three types. The other three base-level constituents (i.e., human agent, information and resource) can facilitate the completion of different tasks.

Human agents are autonomous entities who use their knowledge and skills to conduct production work, process information, and make decisions. Different human agents have different attributes, such as different skill levels, risk attitudes, and working habits. These attributes of human agents directly influence their behaviors, and thus, have a great impact on the outcomes of the tasks they undertake. For example, risk attitude determines the acceptable level of uncertain outcomes for a human agent. A riskseeking human agent is more likely to make decisions that have greater likelihoods of gains, even though the uncertainty of the outcomes is also greater. A risk-averse human agent tends to make decisions that reduce the likelihood of losses. The differences between the risk attitudes of human agents ultimately affect the performance of projects. The attributes of human agents also could change over time. For instance, in an organization with a supportive learning environment, the skill level and productivity of human agents improve over time. Hence, it is important to capture the attributes of human agents and model their behaviors at the base-level of CPSoS in order to better assess the project performance.

Resources are constituents used by human agents to facilitate completion of tasks. In construction projects, resources can be categorized as capital, material, and equipment. One of the important factors affecting the variations in the performance of construction projects is resource uncertainties (e.g., availability and quality of material, availability of capital, and the productivity and condition of equipment). In the previous studies, the uncertainty of resources was considered as a risk factor that can increase the possibilities of project failure. However, no mechanism has been developed to investigate how this uncertainty affects the information flow and dynamic behaviors of human agents, and ultimately lead to performance inefficiencies in projects. In the CPSoS framework, the analysis of resources at the base level highlights the interdependencies between the resource uncertainty and the behaviors of human agents, as well as the information flow. For example, in a construction project, the uncertainty 
related to the quality of concrete delivered to the jobsite not only impacts the quality of the project directly, but also causes other indirect influences on the project by affecting the behaviors of human agents. For instance, if different batches of concrete are tested randomly, a higher uncertainty in the concrete quality leads to a decision by the inspector to increase the frequency of sampling and testing. Hence, it ultimately affects the cost and schedule performance of the project.

The last component of the baselevel constituents in the CPSoS framework is information. Information is an important element for consideration in CPSoS since many interdependencies in project organizations are due to information exchange or sharing. However, the impact of information flow on the project performance was understudied in the previous research. In the base level of CPSoS, two types of information could be identified: static information and dynamic information. Static information remains unchanged throughout a project, for example, building codes, specifications, and historical climate data. On the other hand, dynamic information is generated and can evolve during different phases of a project. Examples of dynamic information include the decisions made by human agents, outcomes of activities, and accidents which sometimes happen unexpectedly in the jobsite. Different attributes (e.g., availability, accessibility, completeness, accuracy, and recency) of information lead to different decisions and actions by human agents, and thus, have an impact on the ultimate performance of construction projects. For example, when a project manager gets a more complete and accurate piece of information regarding to the possibility of a hurricane, his decision related to the risk mitigation strategy and preventive actions could minimize possible impacts on the project. Hence, investigating the attributes of information at the base

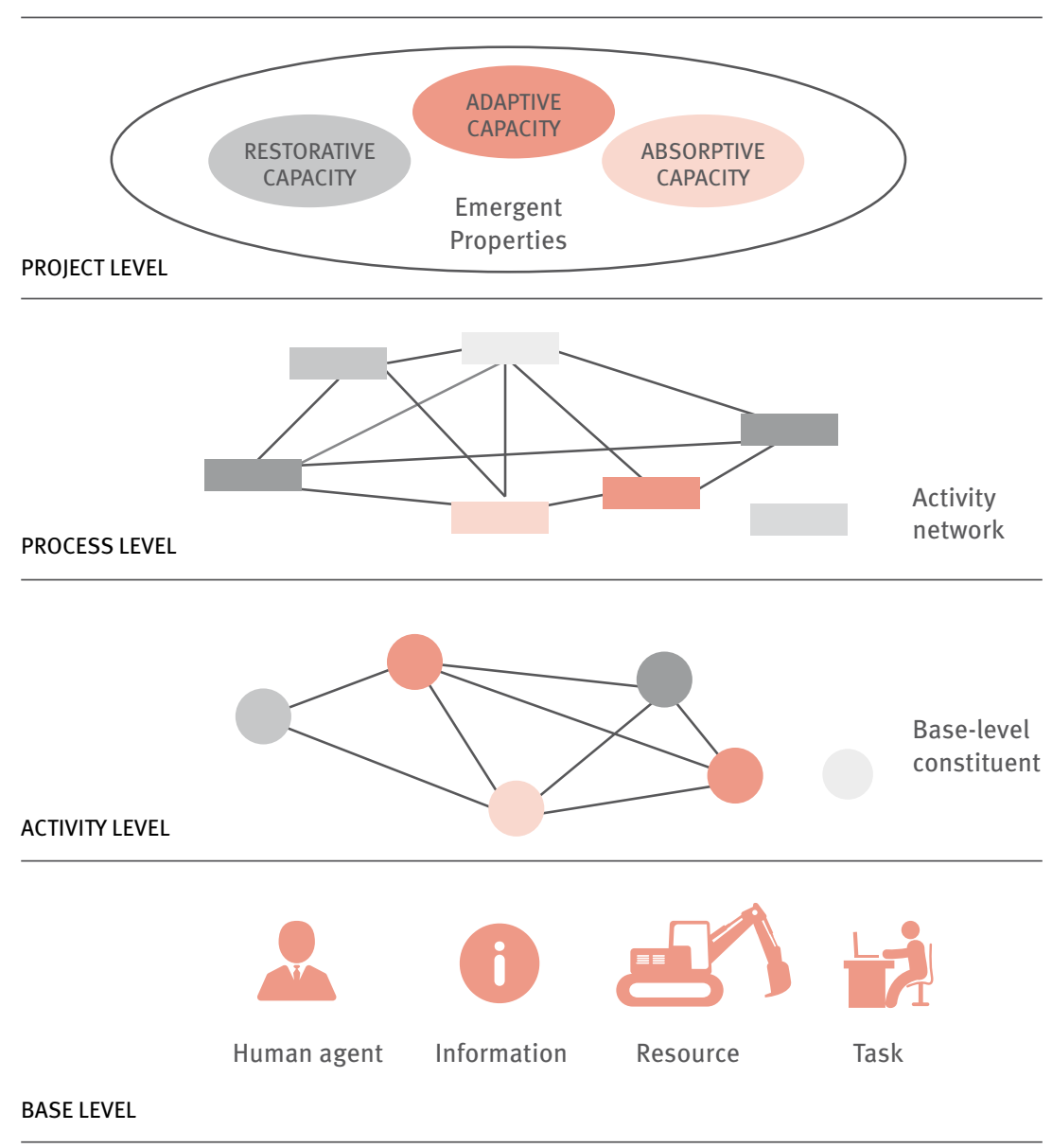

Figure 2 Four levels of analysis in CPSoS framework

level of construction projects can provide a better insight on performance outcomes.

\section{Multi-level aggregation}

The second principle for developing the CPSoS framework is multi-level aggregation. For the purpose of integrated performance assessment, the CPSoS framework analyzes construction projects at four levels: base level, activity level, process level, and project level (Figure 2). Base level is the level where human agents, resources, information and tasks and their attributes are abstracted to capture the microbehaviors of construction projects. The outcomes of the other levels are obtained by aggregating the behaviors and interdependencies of constituents at the levels below. As shown in Figure 2 , the interactions between human agents, resources, information and tasks at the base level are aggregated at the activity level, where the interdependencies between constituents can be used to develop activity networks. The interdependencies between different activities are then aggregated at the process level, where different processes (i.e., sub-systems) in construction projects can be analyzed and assessed in the form of process networks (e.g., design sub-system network, construction sub-system network, and contract administration subsystem network). Finally, the interdependencies between these processes give rise to emergent properties (e.g., absorptive capacity, adaptive capacity, and restorative capacity) at the project level. This four-level analysis facilitates a bottom-up approach for performance assessment from the base level to the 
project level. By the multi-level aggregation, the performance at each level of projects (e.g., activity performance, process performance, and project performance) can be better assessed based on the abstraction and aggregation of the constituents at the base level. At the project level, the investigation of emergent properties is critical for a better understanding of the overall macro patterns in complex project organizations.

\section{Toward a New Paradigm for} Performance Assessment in Complex Construction Projects Using the principles of base-level abstraction and multi-level aggregation, the proposed CPSoS framework addresses the theoretical and methodological limitations of the traditional performance assessment approaches, and provides a structure toward creation of PM 2.0 tools and techniques for integrated performance assessment in complex construction projects. Table 2 summarizes the traits of the CPSoS framework with respect to the theoretical and methodological limitations in the traditional approaches for performance assessment. It is shown that with the base-level abstraction of human agent, resource, information and task in construction projects, and multi-level aggregation from the base level to the project level, many of the theoretical and methodological limitations in the traditional approaches for performance assessment can potentially be addressed.

The capabilities of the CPSoS framework could lead to its utilization for creating tools and techniques toward a new paradigm for integrated performance assessment. These tools and techniques will have different focus, level of abstraction, approach, and methods compared with traditional tools and techniques when assessing performance in complex construction projects (Table 3 ).

\section{Focus}

The focus of traditional performance assessment is to identify and correct undesirable factors in a single process or activity. The impacts of these factors (e.g., poor site management, delay in material delivery, and low productivity in excavation) on project performance are assessed independently. The interdependencies between processes, activities, and constituents and their integrative effects on performance are

\begin{tabular}{l|l|}
$\begin{array}{l}\text { Limitations in Traditional } \\
\text { Performance Assessment }\end{array}$ & Traits of CPSoS framework \\
\hline $\begin{array}{l}\text { Lack of consideration of } \\
\text { autonomous constituents }\end{array}$ & $\begin{array}{l}\text { Autonomy of constituents is considered in CPSoS } \\
\text { framework with modeling the decision-making } \\
\text { capabilities of human agents }\end{array}$ \\
\hline $\begin{array}{l}\text { Lack of consideration of } \\
\text { micro-behaviors }\end{array}$ & $\begin{array}{l}\text { Base-level abstraction in CPSoS framework facilitates } \\
\text { capturing micro-behaviors of constituents below the } \\
\text { process or activity level }\end{array}$ \\
\hline $\begin{array}{l}\text { Lack of consideration of } \\
\text { interdependencies }\end{array}$ & $\begin{array}{l}\text { Interdependencies between constituents in different } \\
\text { levels are considered as links to aggregate the sub- } \\
\text { systems in CPSoS }\end{array}$ \\
\hline $\begin{array}{l}\text { Lack of consideration of } \\
\text { emergent properties }\end{array}$ & $\begin{array}{l}\text { Emergent properties arising from the micro-behaviors } \\
\text { and interactions in project organizations are identified } \\
\text { and emphasized in CPSoS framework }\end{array}$ \\
\hline $\begin{array}{l}\text { Lack of consideration of } \\
\text { evolutions of project }\end{array}$ & $\begin{array}{l}\text { CPSoS framework conceptualizes complex construction } \\
\text { projects as dynamic networks because of the } \\
\text { evolutionary nature of projects }\end{array}$ \\
\hline
\end{tabular}

Table 2 Traits of CPSoS framework

not considered. The new paradigm for performance assessment based on the CPSoS framework proposes emergent properties as a new focus in project performance assessment. Emergent properties capture the integrative features of construction projects through the interdependencies between processes, activities, and base-level constituents. Some of the emergent properties (e.g., absorptive capacity, adaptive capacity, and restorative capacity) can be used to evaluate the ability of project organizations to cope with uncertainties. These emergent properties could be used as leading indicators for predictive assessment and proactively management of construction project performance. For example, the likelihood of cost overruns increases if a project organization with a low adaptive capacity operates in a dynamic and complex environment. In contrast, a project organization can reduce the likelihood of performance variations in a highly uncertain environment by increasing its absorptive, adaptive, and restorative capacities.

\section{Level of abstraction}

The level of abstraction in the existing performance assessment tools and techniques is at process or activity level, which leads to their incapability to capture the dynamic behaviors and interdependencies between constituents at the base-level. Thus, the traditional performance assessment tools and techniques do not consider the unique attributes of constituents at the base level (e.g., human agents have different risk attitudes, or information has different level of accuracy and completeness). The new paradigm, using the CPSoS framework, abstracts construction projects at the base level. The abstraction at the base level facilitates investigating the dynamic microbehaviors in construction projects such as the decision-making and information processing and their impacts on project performance. 


\section{Approach}

Traditional performance assessment tools and techniques follow a top-down approach. In the top-down approaches, it is assumed that the planning and decision-making in projects are based on the command and control settings of hierarchical project structures. However, tools and techniques based on the CPSoS framework will adopt a bottom-up approach. In a bottom-up approach, the performance of a project can be assessed at different levels (i.e., project level, process level, activity level, and base level). The outcomes of the higher levels are obtained by aggregating the behaviors and interdependencies of constituents at the levels below. Using the bottom-up approach, the behaviors and interdependencies at each level of the project can be captured in a network structure. The impact of micro-level behaviors and interdependencies on the project performance at the macro-level is highlighted. Thus, tools and techniques based on the CPSoS framework facilitate integrated project performance assessment at different levels using a bottom-up approach.

\section{Methods}

The main methods used for traditional performance assessment are based on deterministic analysis and discrete event simulation. The CPSoS framework facilitates a better understanding of the dynamic behaviors, uncertainties and interdependencies in construction projects. Thus, other methods could also be adopted for performance assessment in construction project. For example, agent-based modeling can be used to simulate the dynamic behaviors of human agents in obtaining information, processing information, making decisions, and taking actions (Mostafavi et al., 2013). The changes in the attributes of the human agents (e.g., risk attitude or skill level) and their interdependencies can be simulated in agent-based models to investigate performance outcomes in different scenarios. Another possible method is system dynamics. System dynamics has extensively been used in understanding the behavior of complex systems and the effects of causal factors over time (Sterman, 2001). Using system dynamics, the dynamic interdependencies between different processes can be captured based on abstraction and modeling of feedback loops. These simulation methods (e.g., agent-based modeling and system dynamics) could improve the existing tools and techniques in ex-ante assessment of project performance. and methodological limitations pertaining to traditional performance assessment tools and techniques. Thus, the proposed framework can be used for creation of new tools and techniques in performance assessment of construction projects.

Future studies can use the CPSoS framework as a guiding framework toward the creation of integrated theories and methodologies in performance assessment of construction projects in different ways. For example, emergent properties could be investigated as a new dimension in performance assessment because of its significance in understanding the ability of proj-

\begin{tabular}{|c|c|c|}
\hline & $\begin{array}{l}\text { Traditional performance } \\
\text { assessment }\end{array}$ & $\begin{array}{l}\text { Performance assessment using } \\
\text { CPSoS Framework }\end{array}$ \\
\hline Focus & $\begin{array}{l}\text { Standard-alone factors in single } \\
\text { process or activity }\end{array}$ & Emergent properties \\
\hline $\begin{array}{l}\text { Level of } \\
\text { abstraction }\end{array}$ & Process or activity level & Base level \\
\hline Approach & Top-down & Bottom-up \\
\hline Methods & $\begin{array}{l}\text { Deterministic analysis and } \\
\text { discrete event simulation }\end{array}$ & $\begin{array}{l}\text { Agent based modeling, system } \\
\text { dynamics }\end{array}$ \\
\hline
\end{tabular}

\section{Table 3 Comparison between traditional and new paradigm for performance assessment}

\section{Conclusion}

The existing complexity and uncertainty in construction projects call for a paradigm shift toward integrated performance assessment. A SoS framework is proposed in this paper to provide a theoretical lens and methodological structure toward the creation of tools and techniques for integrated performance assessment. The SoS framework is based on the base-level abstraction of constituents and multilevel of aggregation of performance in construction projects. Hence, it facilitates considering dynamic behaviors, uncertainties, and interdependencies between constituents in complex construction projects. The proposed framework addresses the theoretical ect organizations to cope with uncertainty. Based on insights obtained from assessment of emergent properties, the likelihood of project performance deviation could be assessed. The other new dimension of analysis is assessment of the topological structure of project organizations' networks for a better understanding of performance. The traditional social network analysis in project organizations only investigates the interactions between human agents (e.g., who talks, works with, and reports to who). Based on the abstraction of the base-level constituents (i.e., human agent, resource, information and task) in construction project organizations, a meta-network analysis could be used to better understand 
the interconnections with other constituents (i.e., resources, information, and tasks). This understanding is a critical step toward integrated performance assessment. Finally, simulation methods used for assessment of performance in construction projects could adopt agent-based and system dynamics approaches to better capture the attributes of the base-level constituents, their interdependencies, and the feedback loops. The use of these simulation approaches can improve the accuracy of construction simulation models and enhance their application for integrated performance assessment. Using these approaches, new knowledge, tools, and techniques could be created that ultimately lead to an integrated theory of performance assessment in construction projects.

\section{References:}

Chan, D. W. M., and Kumaraswamy, M. M. (1996), "An evaluation of construction time performance in the building industry", Building and Environment, Vol. 31, No 6, pp. 569-578.

Construction Industry Institute. (2012), Performance Assessment. Austin, TX: Construction Industry Institute.

Construction Industry Institute. (2013), Improving the Accuracy and Timeliness of Project Outcome Prediction. Austin, TX: Construction Industry Institute.

Evaristo, J. R., Scudder, R., Desouza, K. C., and Sato, O. (2004), “A dimensional analysis of geographically distributed project teams: A case study", Journal of Engineering and technology Management, Vol. 21, No 3, pp. 175-189.

Gorod, A., Sauser, B., and Boardman, J. (2008), "System-of-systems engineering management: A review of modern history and a path forward”, IEEE System Journal, Vol. 2, No 4 , pp. 484-499.

Hajjar, D., and AbouRizk, S. (1999), “Simphony: An environment for building special purpose construction simulation tools", In proceedings of the 1999 Winter Simulation Conference, pp. 998-1006.

Halpin, D. W. (1977), “CYCLONE-Method for modeling job site processes", Journal of the
Construction Division, 103(3), 489-499.

He, Q., Jiang, W., and Le, Y. (2009), “The study on paradigm shift on project management based on complexity science - project management innovation in Shanghai 2010 EXPO construction program", in 2009 IEEE International Conference on Industrial Engineering and Engineering Management, pp. 603-607.

Iyer, K. C., and Jha, K. N. (2005), "Factors affecting cost performance: Evidence from Indian construction projects", International Journal of Project Management, Vol. 23, No 4, pp. 283-295.

Johnson, C. W. (2006), "What are the emergent properties and how do they affect the engineering of complex systems?" Reliability Engineering \& System Safety, Vol. 91, No 12, pp. $147-1482$.

Kaliba, C., Muya, M., and Mumba, K. (2009), "Cost escalation and schedule delays in road construction projects in Zambia", International Journal of Project Management, Vol. 27, No 5, pp. 522-531.

Karadzic, V., Antunes, P., and Grin, J. (2013), "How to learn to be adaptive? An analytical framework for organizational adaptivity and its application to a fish producer organization in Pirtugal”, Journal of Cleaner Production, Vol. 45, pp. 29-37.

Knudsen, H. K., and Roman, P. M. (2004), "Modeling the use of innovations in private treatment organizations: The role of absorptive capacity", Journal of Substance Abuse Treatment, Vol. 26, pp. 51-59.

Lee, S., Han, S., and Peña-Mora, F. (2009), "Integrating construction operation and context in large-scale construction using hybrid computer simulation", Journal of Computing in Civil Engineering, Vol. 23, No 2, pp. $75-83$.

Levitt, R. E. (2011), “Towards project management 2.0”, Engineering Project Organization Journal, Vol. 1 No 3, pp. 197-210.

Love, P. E. D., Holt, G. D., Shen, L. Y., Li, H., and Irani, Z. (2002), “Using systems dynamics to better understand change and rework in construction project management systems", International Journal of Project Management, Vol. 20, No 6, pp. 425-436.

Lyneis, J. M., Cooper, K. G., and Els, S. A. (2001), "Strategic management of complex projects: A case study using system dynamics”, System Dynamics Review, Vol. 17, No 3, pp. 237-26o. Maier, M. W. (1998), “Architecting principles of system-of-systems”, System Engineering, Vol. 1 No 4, pp. 267-284.

Martinez, J. (1996), “STROBOSCOPE: State and resource based simulation of construction processes", PhD Thesis, University of Michigan, Ann Arbor, MI.

Mostafavi, A., Abraham, D. M., and DeLaurentis, D. A. (2013), “Ex-ante policy analysis in civil infrastructure systems", Journal of Computing in Civil Engineering, Vol. 28, No 5.

Mostafavi, A., Abraham, D. M., DeLaurentis, D. A., and Sinfield, J. V. (2011), "Exploring the dimensions of systems of innovation analysis: A system of systems framework", IEEE System Journal, Vol. 5, No 2, pp. 256-265.

Rechtin, E. (1991), System Architecting: Creating and Building Complex Systems, Englewood Cliffs, NJ, Prentice-Hall.

Sage, A. P., and Cuppan, C. D. (2001), “On the systems engineering and management of systems of systems and federations of systems", Information, Knowledge, Systems Management, Vol. 2, No 4, pp. 325-345.

Sheffield, J., Sankaran, S., and Haslett, T. (2012), "System thinking: Taming complexity in project management”, On the Horizon, Vol. 20, No 2, pp. 126-136.

Sterman, J. D. (2001), “System dynamics modeling: Tools for learning in a complex world”, California Management Review, Vol. 43, No 4, pp. 8-25.

Taylor, T. R., and Ford, D. N. (2008), “Managing tipping point dynamics in complex construction projects", Journal of Construction Engineering and Management, Vol. 134, No 6, pp. 421-431.

Zhang, H. (2007), “A redefinition of the project risk process: Using vulnerability to open up the event-consequence link", International journal of project management, Vol. 25, No 7 , pp. 694-701.

Zhu, J, and Mostafavi A. (2014), “Towards a new paradigm for management of complex engineering projects: A system-of-systems framework", In IEEE 8th Annual Systems Conference (SysCon), pp. 213-219.

Zhu, J., Mostafavi, A., and Romero, G. (2014), "Project organizations as complex system-ofsystems: Integrated performance assessment at the interface of emergent properties and uncertainty", In Engineering Project Organizations Conference (EPOC). Winter Park, CO. 